\title{
Decoding affective communication in intimate relationships
}

Gisela Trommsdorff \& Helga John 


\begin{abstract}
Situational and personality variables influencing the accurate understanding of partners' commurications in intimate couples were studied. The situation was varied by inducing either partner-focused or self-focused attention. The personality variables were genderrole attitudes, control orientation, and empathy. Thirty couples who had been living together for at least 12 months discussed an issue which was important to both partners. Afterwards, each selected their partner's most 'important' statement from their videotaped discussion. The two statements were then rated by each of the partners in respect of their own and their partner's emotional reaction to them (intentionally sent and actually experienced emotions). Analyses of variance with correctness of decoding as a dependent variable demonstrated strong effects of other-focused attention and gender as independent variables. Femininity and secondary control correlated positively with correct decoding. These results are interpreted in a theoretical framework of empathy and communication.
\end{abstract}

\title{
INTRODUCTION
}

The process and quality of interpersonal communication depends, among other factors, on the mutual and accurate understanding of the partner's intended messages. Both the sender and the recipient of messages can contribute to the 'correct' or distorted decoding. It is especially interesting to study whether correct decoding in intimate relationships is symmetrical or whether certain systematic influences distort decoding accuracy. If adequate sensor-motor and cognitive-emotional abilities have developed in both persons, the partner's emotions should be correctly decoded. Social perception however, is also influenced by cognitive-motivational processes as well. Correct decoding may thus depend on the motivation and ability of the observer to decode. 
The communication of affective meaning is especially vulnerable to distortion. Depending on the quality of the interpersonal relationship, personality characteristics, situational conditions, and the kind of affective message, such messages could be encoded more or less ambiguously and decoded more or less 'accurately'. In order to identify possible personality and situational factors for the accurate communication of affective messages in close relationships, the present study focuses on accuracy in the decoding of affective messages.

The relevant perceptual processes may involve a specific sensitivity which underlies empathic responding ('sympathy'). This part of the communication process has received considerable interest in the literature on 'empathy' ('sympathy') ( $c f$. Goldstein and Michaels, 1985; Eisenberg, 1986; Eisenberg and Strayer, 1988). However, studies on empathy have focused for the most part only on sadness of the other person. It may be that different emotions are encoded and decoded differently. Therefore, naturalistic communication situations in which various emotions are relevant are needed to study the conditions for general accurate decoding. One goal of the present study is to create naturalistic communication.

This study is related to research on 'empathic accuracy' (Ickes, Stinson, Bissonnette, and Garcia, 1990). Ickes et al. (1990) understand 'empathic accuracy' as '(a) a skill, ability, or facility (b) to understand, apprehend, infer, interpret (c) with accuracy (d) the private, covert, subjective (e) phenomenological reality, mental experience, thoughts and feelings (f) of some other person(s)' (p. 731). However, besides the cognitive ability to understand the feelings of the other person correctly, the motivation to decode correctly should also be taken into account. Therefore, the effect of this motivation will be studied here. It may be activated by situational conditions, such as a cognitive-affective focus on the feelings of the other person.

A further goal of this study is to isolate the effects of person and situation variables on the accurate decoding of the partner's emotions in realistic dyadic interactions in which heterosexual partners communicate.

Also in contrast to previous studies, the natural context means that the topic of decoding is of personal relevance to the subjects and the intimate partner's affective messages are part of a natural conversation with the subject. This gives the study increased ecological validity.

\section{Person variables}

Gender may be related to differential competence and motivation in the decoding of other people's emotions on account of different socialization experiences and related gender role orientations. However, most of the literature on gender differences in empathy and decoding ability has focused simply on sex differences between males and females, without taking into account the respective gender role orientations that affect empathic accuracy.

The literature on sex differences in empathy and decoding ability is controversial. In their review of 29 papers, Maccoby and Jacklin (1974) came to the conclusion that there were no sex differences, and Block (1973) came to the same conclusion in her reexamination of their corpus. In contrast, in his review of nine articles, Hoffman (1977) found that females scored higher on empathy than did males. Hoffman (1977) differentiated between measures of empathy, role-taking, and social sensit- 
ivity. In their review on sex differences in empathy, Eisenberg and Lennon (1983) took into account the various methods for the assessment of empathy. They found no sex differences for unobtrusive or for physiological methods, but did for selfreports.

The results on sex differences in affective role-taking are also ambiguous. In his review, Hoffman (1977) did not find any sex differences. However, as Hall (1978) has noted, Hoffman omitted a large body of research on sex differences in the decoding of nonverbal cues. Hall (1978) reviewed 75 empirical studies on the ability to decode nonverbal communication related to another person's affective state. Females decoded visual and auditory cues better than males. In their review, Eisenberg and Lennon (1983) demonstrated that with increasing age (subjects were 9 years and older), females lose their advantage in decoding covert nonverbal cues. Empirical data indicate that they may gain more competence for decoding overt cues (Zuckerman, Blanck, DePaulo and Rosenthal, 1980). Interestingly, these studies on sex differences did not explicitly analyse the possible effects of gender role attitudes and gender stereotypes but simply speculated about the effects of gender on socialization.

Differences in certain areas of decoding accuracy may be related to gender-specific learning experiences and the motivation to decode correctly. Females may be rewarded more often for decoding accurately than males as part of their expected gender role behaviour. They may come to conceive of such accuracy as an important aspect of their self-concept and social competence. Thus, empathic accuracy may be a result of gender-specific socialization. Accordingly, one may expect that gender role attitudes, arising from gender-specific socialization, should be related to empathic accuracy. Persons with high 'feminine' and low 'masculine' gender role attitudes may show a higher level of competence and motivation for empathic accuracy.

Women have often been described in terms of having had more learning experiences that facilitate their taking the needs of other persons into account. In comparison with men, women are considered to be socialized into understanding their social environment in more socio-emotional than rational and instrumental terms and to develop a more social-oriented self concept (Parsons and Bales, 1955; Bakan, 1966; Block, 1973; Maccoby and Jacklin, 1974; Spence and Helmreich, 1978). The results on gender role stereotypes are generally in line with this description.

Along similar lines, Bakan (1966) and Gilligan (1982) describe 'feminine' versus 'masculine' orientations to the social environment: The 'feminine' orientation implies a sense of 'communion' that is, a strong sense of the feelings and needs of other persons. In contrast, the 'masculine' orientation implies a sense of 'agency' that is, a strong need for self-assertion and self-expansion. For the 'feminine' person, a sense of communion and relatedness constitutes an essential quality in social relations.

'Femininity' of orientation is understood here, in accordance with Spence and Helmreich (1978), as a generalized attitude which gives more weight to mutual understanding in a social climate of 'communion' than to self-assertive principles of 'agency'. For 'feminine' as compared to 'masculine' persons, we may expect more empathy for other persons and possibly also more competence and motivation to decode other persons' emotions accurately.

Actually, Spence and Helmreich (1978) suggested a positive correlation between femininity and empathy and a negative correlation between masculinity and empathy. This was found by Foushee, Davis, and Archer (1979): self-ratings of femininity 
were positively related to the self-reports of empathy by men and women; self-reports on masculinity were negatively correlated with self-reported empathy.

However, empathy is not the same as accuracy. Though one may expect to find a close relationship between empathy and decoding accuracy, this relationship has not yet been studied empirically. Accordingly, the present study will analyse the relationship between biological sex, gender role orientations, empathy, and accuracy for intimate heterosexual dyads. The hypothesis will be tested that women as compared to men, and 'feminine' as compared to 'masculine' persons, decode the emotional messages of their partner more accurately.

\section{Control orientation}

The belief in 'primary' or secondary' control is another personality variable which may be related to accuracy. According to Rothbaum, Weisz, and Snyder (1982) and Weisz, Rothbaum, and Blackburn (1984), people differ in the way they structure the relationship between themselves and the environment. Their conceptualization of 'primary' control orientation implies processes of changing the environment according to one's own needs and goals, while the belief in 'secondary' control resembles the process of accommodation and an internal restructuring of one's own needs, evaluations, and goals as a function of the perceived realities of the environment. Empirical studies demonstrate culture-specific differences in the preference of 'primary' as opposed to 'secondary' control orientation which seem to be related to a different emotion-based socialization experience and interpersonal exchange (Trommsdorff, 1985, 1989).

In the case of 'secondary' as compared to 'primary' control orientation, one may assume a tendency towards 'communion' (in contrast to 'agency') and more accuracy for the other person's emotions. On the other hand, one may also assume that 'agency' as well as 'primary' control oriented persons decode more correctly since understanding the other person's emotions can also be used strategically in order to increase one's effective manipulation of the social environment. The data will be examined with respect to these hypotheses.

\section{Situational influences on decoding}

It is assumed here that accuracy is based upon an acquired competence and specific motivation. The motivation may be activated by situational conditions such as a cognitive-affective focus on the feelings of the other person. For the correct decoding of emotions, a person has to focus more on the affective state of the partner and less on other objects or on oneself. More 'correct' decoding of emotions should therefore occur for strong partner-focused attention than for weak partner-focused attention. First, more information on the partner's affective state is received and can be decoded. Second, a situationally induced orientation toward the partner (and less perceptual focusing on the self) should activate the motivation to diagnose the emotional state of the other person. The hypothesis will be tested that the perceptual focus on the other person, instead of oneself, increases decoding accuracy. 


\section{Accuracy of decoding}

A communicated message may transport emotional information from the sender; it may also evoke emotional reactions in the receiver. In the present study, only the aspect of the 'correct' decoding of intended emotional messages is analysed as an indicator of empathic accuracy, using the method derived by Gottman, Notarius, Markman, Banks, Yoppi, and Rubin (1976) to study the differences between communicative intent and communicative impaci (received message).

The present investigation is concerned only with those personal and situational factors which promote the 'correct' decoding of the partner's emotions. According to the model of Gaelick, Bodenhausen, and Weyer (1985), a 'correct' decoding of a communication takes place when the sender's message corresponds to the interpretation of the recipient ( $c f$. Gottman et al., 1976). The authors conceptualize an interaction between two persons as a series of communicative acts. Each communication consists of a verbal statement or a series of statements accompanied by various nonverbal cues. One communication can simultaneously express specific emotions of the communicator and produce emotions in the recipient. The model distinguishes between five parameters:

(1) Intent, the affect or emotion that the sender intends to convey to the recipient.

(2) Perceived intent, the recipient's perception of the sender's intent.

(3) Reaction, the recipient's affective reaction to the communication.

(4) Expected reaction, the sender's expectation of how the recipient will react.

(5) Perceived reaction, the sender's perception of how the recipient actually reacted.

The model of Gaelick et al. (1985) described the relationship between these five parameters. The present study will only examine to what extent the intended emotional communication of the sender (intent) is equivalent to the recipient's perception of this communication (perceived intent) $(1$ and 2$)$ and to what extent the emotional reaction of the recipient of the communication (reaction) is equivalent to the communicator's perception of this reaction (perceived reaction) (3 and 5). (No reference is made to messages that the sender did not intend to send but which are validly interpreted by the recipient).

In summary, the concern here is with the extent to which certain personality variables and situational conditions influence the accuracy of the decoding of the partner's emotions.

\section{METHOD}

\section{Sample}

Altogether. 30 couples $(N=60)$ participated in the study. They had been living together for at least 12 months. The subjects were informed about the study by pamphlets in restaurants, shops, and on the university campus in Aachen. In order to ascertain whether the subjects were partners in close relationships, we inquired as to how long the couples had been living together. Subjects from all age groups were included (age: 20 to 68 years; $N=33$ were 31 years and older; $N=27$ were sounger). The duration of living together varied between 1 and 38 years; $N=28$ 
had lived together for 10 or more years (they were married, the others were not). The subjects also varied with respect to education and occupation $(N=37$ had been educated at a German 'Gymnasium' and had graduated by passing the 'Abitur'examination; $N=32$ held a middle-class occupation or worked in an academic position). Each couple obtained a small fee ( 15 German marks) after the experiment.

\section{Procedure}

Individual experiments were carried out with each couple. In order to maximize verbal and nonverbal communication, the partners were seated vis-à-vis at a table ('talk-table': cf. Gottman et al., 1976). A monitor was placed in front of each subject. The subjects were welcomed, seated, and instructed. The couples were first asked to choose a topic of medium importance to them which they had recently discussed without reaching an agreement. This instruction was given in order to ensure that only moderate conflicts would be chosen as stimulus material. The experimenter did not interfere when the couples were deciding on the topic. All couples were able to agree on a topic within a few minutes without experiencing any difficulties. Typical topics of conflict were, e.g. visiting relatives; buying a piece of furniture; doing housework. After the couple had decided on a topic, they were asked to discuss it for 15 minutes. The subjects were informed that their discussion was being videotaped. During the discussion, the experimenter left the room. The discussion was observed by the experimenter on a monitor in an adjoining room. Although the partners were very involved in their discussions, no serious conflicts occurred; the discussions shifted between tense and relaxed periods. After 15 minutes, the experimenter came back and asked each of the subjects to choose the one statement of their partner which they considered to be the most important one. These statements were to be rated by the subjects. To that end, subjects were asked to watch their videotaped discussion (15 minutes). The experimenter made sure that both of the partners integrated the chosen statements correctly into the context of the discussion; thus, each partner knew which statement his/her partner was referring to. Then, the subjects were asked to rate their own emotions and their partner's emotions on the respective scales (Emotions list) (decoding task for the self-chosen communication and the communication chosen by the partner) (duration about 20 minutes). The experimenter checked whether the subjects were following all instructions. Next, the German version of the Empathy Scale of Mehrabian and Epstein (1972) (about 10 minutes), the German version of the PAQ (Spence, Helmreich and Stapp 1974, 1975) (about 10 minutes), and the questionnaire of control-orientation (Züblin, 1986) (about 15 minutes) were filled out. After that, the subjects were thanked for their participation, handed the honorarium, and dismissed. This procedure was pretested in several pilot studies.

\section{Instruments}

Independent variables

fte'ntion-focusing The independent variable 'attention-focusing' was manipulated by instruction. (i) Self-focused attention: The instruction for one half of the couples at the beginning of the experiment was: 'Please concentrate exclusively on 
your own feelings and expectations and try to keep your own point of view in mind'. (ii) Partner-focused attention: The other half of the couples were instructed: 'Please concentrate exclusively on your partner's feelings and expectations and try to understand him/her'. In order to remind the subjects of this instruction during the experiment, the experimenter put a paper with this instruction written in red capital letters in front of the subject's seat after having instructed the couples orally. The experimenter said: 'I have noted the instruction on this paper so that you do not forget it during the experiment. It is very important that you keep this instruction in mind'. The couples were randomly assigned to one of these two conditions. Again, the experimenter checked whether the subjects could follow these instructions. No difficulties occurred.

Gender Each couple consisted of a female and a male partner.

Direction of decoding In accordance with the procedure of Gaelick et al. (1985), the subjects were asked to choose one statement of their respective partners. This statement was evaluated by the partners according to the emotion which they believed the communicator had intended to communicate (intent) and the emotional reaction which was perceived by the recipient (perceived intent). To this end, each of the partners was asked to choose one statement of his/her own and one statement of his her respective partner. These statements were supposed to represent the most important communication. Then, one statement of each partner was to be evaluaied by the subjects. Accordingly, each partner produced one evaluation as the sender and one evaluation as the receiver of a communication (self- and partner-rating).

\section{Dipendent variables}

Decoding of emotions This is defined here as the description of the emotions experienced by the partner. The decoding of an emotion was regarded as accurate when the self- and the partner-ratings (ratings by both partners) were equivalent (intent

$=$ perceived intent; reaction $=$ perceived reaction $)$.

The quality of emotions and its quantity (intensity) were rated on a list of 18 different emotions (Emotions List). This list included the emotions discussed by Ekman. Friesen and Ellsworth (1972), Izard (1977), and Plutschik (1980). The emotions were presented in the following order: anger, understanding, disappointment, affection. fear, shame, pride, interest, sorrow, gladness, trust, aversion, sadness, dislike. astonishment. arousal. (Examples are: 'I was angry', 'I felt understanding'). The list was headed by one item to test whether emotions actually arose at all: 'I was affected by the situation'. The list of emotions was rated for the partner's emotions: another list (containing the same items) was rated for the subject's own emotions. All items were rated on a 4 -point scale $(1=$ strongly disagree $\ldots .4=$ strongly agree). Each of the two sources of communication were rated in this way.

(a) Description of subject's own emotions related to his/her own statement; (b) description of partner`s emotions which subject (communicator) believed to be evoked hy his her statement. 


\section{Recipient}

(a) Description of emotions which subject (recipient) believed to be experienced by the partner (communicator) when he/she made this statement; (b) description of subject's own emotions which were evoked by this statement.

The instruction read as follows: (a) 'How well do the following 18 terms represent the feelings you had when you made your statement?' (b) 'How well do the following 18 terms represent the feelings your partner had when you made your statement?'

(c) 'How well do the following 18 terms represent the feelings your partner had when he/she made this statement?' (d) 'How well do the following 18 ter.ns represent the feelings you had when your partner made this statement?'

In order to calculate the degree of correctness of the decoding, Spearman rank correlations were calculated (a) for the recipient's decoding: between the emotional reaction intended by the communicator and the emotion perceived by the recipient; and (b) for the communicator's decoding: between the recipient's emotional reaction and the emotional reaction perceived by the communicator. Since, for each partner, one communication had been chosen for which one partner was the communicator and another communication for which this partner was the recipient, two scores for recipient-decoding and two scores for communicator-decoding were computed for each couple.

\section{Personality tests}

In order to measure further 'other-focused attention' variables, several personality tests were employed.

Empathy The questionnaire of Mehrabian and Epstein (1972) was used. Subjects had to rate 33 statements about empathic and non-empathic behaviour on a 9-point scale $(+4=$ very strongly agree $\ldots-4=$ very strongly disagree $)$. Each subject obtained one score which was equal to the sum of the ratings for all of the 33 items. Here, the German translation by Haag (1980) was used.

Masculinity/femininity Gender role attitudes were measured by the 'Personal Attributes Questionnaire' (PAQ) developed by Spence et al. (1974, 1975). In this study, the German translation of the short form of the PAQ (Runge, Frey, Gollwitzer, Helmreich, and Spence, 1981) was used. The validity and reliability of this version is satisfactory. The questionnaire contains 24 bipolar items for self-rating. It consists of three subscales. Each subscale contains eight bipolar items which represent the dimensions 'masculinity' (M-scale) and 'femininity' (F-scale) (these are regarded as separate dimensions for each sex) as well as 'masculinity-femininity' (M-F-scale). The M-scale contains items which are considered to be socially desirable for both sexes, although males are believed to score higher than females. Conversely, the F-scale (femininity-scale) contains items which are considered to be socially desirable for both sexes, although females are believed to possess these characteristics to a greater extent than males. The bipolar M-F-scale contains items which differentiate between the sexes; this scale is keyed in a masculine direction and is used as an additional indicator for masculinity. The 24 bipolar items of the PAQ are rated on 5-point scales (e.g. $A=$ not aggressive $\ldots E=$ very aggressive). For each item, the subjects were asked to choose the letter which they believed described them best. For each subject, the eight items of one scale were summed. 
Control orientation Methods for measuring 'primary' and 'secondary' control orientation in children (Brotman-Band and Weisz, 1988) and in mothers (Trommsdorff, 1989) were not useful to our purposes. Therefore, we chose a method developed by Flammer and his coworkers which was tested for the measurement of control orientation with 150 adolescents (Züblin, 1986; Flammer, Züblin, and Grob, 1988). In this questionnaire, 12 different frustrating or stress-producing situations of everyday life are described which induce different responses of control orientation (Example: 'A person who was a good friend until now is suddenly rejecting you'). Four possible reactions were presented to the subject; each was an, alternative to control the situation or to solve the problem:

Direct primary control: 'I would speak to him or somehow try to make him/her become a good friend'.

Indirect primary control (by manipulating a powerful person): 'I would ask someone to speak with him/her. Perhaps he can induce this person to be friendly to me again'.

Loss or abandonment of attempt to control: 'I would be sad about this behaviour, but it cannot be helped'.

Secondary control: 'I would look for new friends. With these, I shall certainly get on better than with this one'.

Subjects distributed 10 points among the four alternatives. The more the subject preferred one of the four alternatives, the more points were given to this alternative. The scores for each of the four choices were summed over all 12 items for each subject (see John (1988) for a complete version of the methods in German).

\section{RESULTS}

The responses for various emotions were not analysed separately but summed for all emotions. The effects of situation and personality factors were tested by analyses of variance and covariance with repeated measurement. Decoding accuracy was measured by two scores for each subject: The Spearman rank correlation (a) between the communicator's intended emotions and the emotions perceived by the recipient and (b) between the recipient's emotional reaction was calculated.

The results of the univariate analysis of variance with repeated measures $(A=a t-$ tention-focusing; $\mathrm{B}=$ gender; $\mathrm{C}=$ communicator/recipient-decoding) clearly showed main effects for the factor attention-focusing in the expected direction $(F=37.30$; $d f=1 / 25 ; p<0.01)$ : The partner's emotions were decoded more correctly when attention was partner-focused than when it was self-focused. Gender showed the effect expected: Women decoded more correctly than men $(F=7.42 ; d f=1 / 25 ; p<0.01)$. As expected, the communicator/recipient-decoding direction did not have any influence. This factor will not be taken into account in further analyses (means see Table 1).

Comparisons of the mean values showed that for some of the control variables significant differences between men and women occurred: Men, as compared to women. showed less empathy $(z=2.81, p<0.01)$, had higher scores for masculinity $l=-2.60, p<0.01)$ and masculinity-femininity $(z=-2.44, p<0.01)$, and showed a preference for more direct primary control $(z=-1.95, p<0.05)$ (see Table 2).

Correlations between each of the control variables and the accuracy of decoding 
Table 1. Accuracy of decoding of emotions under conditions of attention-focusing on self or partner

\begin{tabular}{lcccccccc}
\hline & \multicolumn{2}{c}{ Self } & \multicolumn{2}{c}{ Partner } & \multicolumn{2}{c}{ Average } & $N$ \\
& $\bar{x}$ & S.D. & $\bar{x}$ & S.D. & $\bar{x}$ & S.D. & \\
\hline Communicator & & & & & & & \\
$\quad$ Women & 0.29 & 0.32 & 0.75 & 0.19 & 0.52 & 0.46 & 30 \\
$\quad$ Men & 0.24 & 0.22 & 0.59 & 0.32 & 0.41 & 0.42 & 30 \\
$\quad$ Average & 0.27 & 0.16 & 0.67 & 0.28 & 0.47 & 0.45 & 30 \\
Recipient & & & & & & & \\
$\quad$ Women & 0.34 & 0.24 & 0.72 & 0.17 & 0.53 & 0.44 & 30 \\
$\quad$ Men & 0.20 & 0.25 & 0.71 & 0.22 & 0.45 & 0.51 & 30 \\
$\quad$ Average & 0.26 & 0.26 & 0.71 & 0.08 & 0.49 & 0.47 & 30 \\
In total (communicator & & & & & & & \\
and recipient) & & & & & & & \\
$\quad$ Women & 0.32 & 0.16 & 0.73 & 0.13 & 0.52 & 0.46 & 30 \\
$\quad$ Men & 0.27 & 0.14 & 0.65 & 0.24 & 0.44 & 0.46 & 30 \\
$\quad$ Average & 0.45 & 0.21 & 0.68 & 0.20 & 0.48 & 0.46 & 30 \\
\hline
\end{tabular}

For each subject Spearman rank correlation coefficients for.sending and decoding emotions were computed (here, mean $r$ ).

Table 2. Accuracy of decoding emotions for different situations and personality variables

\begin{tabular}{|c|c|c|c|c|c|c|c|}
\hline & \multicolumn{2}{|c|}{ Self } & \multicolumn{2}{|c|}{ Partner } & \multicolumn{2}{|c|}{ Average } & \multirow[b]{2}{*}{$z$} \\
\hline & $\bar{x}$ & S.D. & $\bar{x}$ & S.D. & $\bar{x}$ & $N$ & \\
\hline \multicolumn{8}{|l|}{ Empathy } \\
\hline Women & 55.20 & 24.19 & 55.73 & 27.00 & 55.47 & 30 & \\
\hline Men & 36.27 & 17.53 & 39.47 & 19.88 & 37.87 & 30 & $2.81^{*}$ \\
\hline \multicolumn{8}{|c|}{ Masculinity } \\
\hline Women & 15.33 & 5.78 & 15.60 & 4.60 & 15.47 & 30 & \\
\hline Men & 23.60 & 4.03 & 21.27 & 4.04 & 22.44 & 30 & $-2.60 *$ \\
\hline \multicolumn{8}{|l|}{ Femininity } \\
\hline Women & 23.87 & 4.57 & 23.40 & 5.15 & 23.64 & 30 & \\
\hline Men & 21.00 & 5.13 & 23.60 & 3.27 & 22.30 & 30 & 1.14 \\
\hline \multicolumn{8}{|c|}{ Masculinity-femininity } \\
\hline Women & 11.53 & 3.46 & 10.60 & 3.70 & .11 .07 & 30 & \\
\hline Men & 18.07 & 3.28 & 14.07 & 3.15 & 16.02 & 30 & $-2.44 \dagger$ \\
\hline \multicolumn{8}{|c|}{$\begin{array}{l}\text { Secondary control } \\
\text { orientation }\end{array}$} \\
\hline Women & 51.00 & 19.41 & 55.20 & 20.90 & 53.10 & 30 & \\
\hline Men & 39.60 & 13.72 & 49.20 & 22.84 & 44.40 & 30 & 1.62 \\
\hline \multicolumn{8}{|c|}{$\begin{array}{l}\text { Direct primary control } \\
\text { orientation }\end{array}$} \\
\hline Women & 45.13 & 19.00 & 39.40 & 15.37 & 42.27 & 30 & \\
\hline Men & 52.20 & 14.24 & 50.07 & 20.11 & 51.14 & 30 & -1.95 \\
\hline \multicolumn{8}{|c|}{$\begin{array}{l}\text { Indirect primary control } \\
\text { orientation }\end{array}$} \\
\hline Women & 9.60 & 6.78 & 11.20 & 5.27 & 9.05 & 30 & \\
\hline Men & 13.20 & 7.08 & 10.40 & 5.42 & 11.80 & 30 & -0.80 \\
\hline \multicolumn{8}{|c|}{$\begin{array}{l}\text { Loss or renunciation of } \\
\text { control }\end{array}$} \\
\hline Women & 14.27 & 10.94 & 14.20 & 10.05 & 14.14 & 30 & \\
\hline Men & 15.00 & 7.19 & 11.00 & 7.82 & 13.00 & 30 & 0.22 \\
\hline
\end{tabular}


Table 3. Spearman rank order correlations between control variables and accuracy of decoding emotions

\begin{tabular}{|c|c|c|c|c|c|c|c|c|}
\hline & $\mathbf{M}$ & $\mathrm{F}$ & MF & EM & KP & KS & $\mathrm{KJ}$ & KV \\
\hline $\begin{array}{l}\text { M } \\
\text { F } \\
\text { MF } \\
\text { EM } \\
\text { KP } \\
\text { KS } \\
\text { KJ } \\
\text { KV } \\
\text { Sum }\end{array}$ & $\begin{array}{c}-0.1801 \\
0.5081^{*} \\
-0.4866^{*} \\
0.5322^{*} \\
-0.4081^{*} \\
0.1423 \\
-0.2244 \\
-0.0989\end{array}$ & $\begin{array}{c} \\
-0.3686^{*} \\
0.3740^{*} \\
-0.3645^{*} \\
0.5067^{*} \\
-0.1548 \\
-0.3017 \dagger \\
0.3460^{*}\end{array}$ & $\begin{array}{c} \\
-0.3633^{*} \\
0.3835^{*} \\
-0.3399^{*} \\
0.1805 \\
-0.1219 \\
-0.3707^{*}\end{array}$ & $\begin{array}{c} \\
-0.5462 * \\
0.6001 * \\
-0.1994 \\
-0.1302 \\
0.1255\end{array}$ & $\begin{array}{c} \\
-0.8923 * \\
0.1618 \\
-0.2202 \\
-0.2078\end{array}$ & $\begin{array}{c} \\
-0.4567^{*} \\
-0.2661 \dagger \\
0.2514\end{array}$ & $\begin{array}{r} \\
-0.0014 \\
0.0541\end{array}$ & -0.1984 \\
\hline
\end{tabular}

emotions (the sum of communicator- and recipient-decoding because differential effects of the factor 'decoding-direction' did not occur) were significant with genderrole attitudes (positive correlation with femininity: $r=0.35 ; p<0.01$; masculinityfemininity: $r=-0.37 ; p<0.01)$, and secondary control orientation $(r=0.25$; $p=<0.05$ ). The underlying effect is largely shared between secondary control and femininity: The correlation is only 0.09 when femininity is partialled out. Accuracy of decoding did not correlate significantly with masculinity $(r=-0.10)$, empathy $(r=0.13)$, direct primary control $(r=-0.21)$, indirect primary control $(r=0.05)$, or abandonment of control $(r=0.20)$ (for two-tailed tests, the critical score for $p=0.05$ is $r=+/-0.25$ ) (see Table 3).

\section{DISCUSSION}

The results clearly show the influences of attention-focusing and gender on empathic accuracy when decoding emotions. Under the condition of partner-focused attention, decoding performance was more accurate and women identified their partner's emotions more accurately than men did. The direction of decoding (sender emotions or receiver emotions) did not influence the accuracy of decoding. The correlations between control variables and the accuracy of decoding demonstrate the relevance of gender role attitudes and control orientation with 'femininity' and 'secondary' control orientation correlating positively.

These results support the assumption that conditions which direct the focus of attention toward the partner enable one to make more 'correct' judgments of the partner's intended emotions.

Women manage to do this better than men. Our results are in line with those results of Hall (1978) and Eisenberg and Lennon (1983). Specific gender role attitudes characterize men and women: Men show more 'masculine' gender-role attitudes than women, which is consistent with the results of Spence et al. $(1974,1975)$. Our data also show that women are not more 'feminine' than men. This may indicate a recent 
tendency of men to adopt 'feminine' attitudes without simultaneously departing from 'masculine' orientations. Or perhaps females are adhering less to 'feminine' orientations. In general, our results indicate that women, unlike men, may be more oriented toward the feelings of their partner and have learned to correctly perceive their partner's intended emotions. This cannot be generalized to persons with less 'masculine' orientation.

The women in our study are characterized by a pattern of additional characteristics besides their decoding accuracy; they are low on 'primary' control orientation and high on empathy. These variables seem to have one thing in common: These attitudes are characterized by an orientation toward other persons' emotions, needs, and goals rather than an orientation toward oneself. This emotional and cognitive orientation toward other persons may be based on a stronger sense of 'communion' rather than of 'agency' (Bakan, 1966). Here, Gilligan's (1982) assumption of a stronger relational orientation of females than of males seems in line with our data.

However, whether or not this person-orientation is related to empathy - feeling with the other person (sympathy) - is not yet clear. In our study, the control variable 'empathy' did not correlate significantly with decoding accuracy. This global measure of empathy may not be valid. Recent literature has demonstrated the necessity of measuring the different components of empathy by using specific indicators, especially when studying the function of empathy in actual behaviour (cf. Trommsdorff, in prep.). The main components of empathy can be differentiated into the cognitive understanding of emotions, affective role-taking, and emotional sympathizing (Eisenberg, 1986; Trommsdorff, 1991). Let us assume that the first and second component of empathy can be measured successfully by decoding accuracy. The experimental results have shown that attention-focusing on the partner indeed increases decoding accuracy for both men and women. However, beyond this situation-induced perceptual accuracy, more is needed for empathic responding - feeling with the other person implies more than empathic accuracy. More detailed studies on the development of empathy and its components may allow us to differentiate between empathic accuracy and empathic responding (sympathy) (cf. Trommsdorff, in prep.).

Another question arises for future research. Though we had differentiated between different types of emotions in our 'List of Emotions', we were not able to analyse whether or not the quality and kind of emotions encoded by men and women were different on account of sample size: For example, women may be more skilled in masking certain emotions; they may communicate more indirectly or subtly and thereby make it more difficult for men to decode accurately. Here, questions arise regarding whether and in which way encoding abilities are related to empathic decoding. It should be clarified which emotions induce which degree of difficulty in decoding and whether such difficulty depends on the person's experience in communication of emotions.

To summarize, our results demonstrate clear effects of gender and situational attention-focusing on the accuracy of decoding. It seems that an explicit orientation to other persons contributes to empathic accuracy. Such an orientation is related to certain personality variables like 'femininity' and 'secondary' control orientation and can be induced by certain situational conditions like focusing on the partner instead of on oneself.

While the concept of control orientation has been used by Weisz et al. (1984) and Flammer (1990) to differentiate between modes of coping, it also may be assumed 
on the basis of our results that different beliefs in how to deal with the social environment and different modes of communication like empathic accuracy are related to control orientation.

Different persons prefer different control orientations as well as different strategies of interacting with their social environment. In the case of 'feminine' and 'secondary' control orientation the goal is to behave in accordance with the environment (accommodation). In the case of 'masculine' and 'primary' orientation, an attempt is made to change the environmental conditions (directly or indirectly) to fit one's own goals (assimilation of environmental conditions).

'Feminine' and 'secondary' control oriented persons decode more accurately since they seem to refrain from self-focused attention. Interestingly, the lowest degree of empathic accuracy occurred in the case of situationally-induced self-focused attention and in the case of abandonment of attempt to control. Here, the other person's mental condition, his/her intentions, feeling, and emotions get 'out of focus' for the observer, and decoding becomes distorted.

As our results show, empathic accuracy can be activated by intended focusing on the other person. Accordingly, differences in empathic accuracy may not simply be due to differential abilities or beliefs; they may be due to motivational differences like empathic motivation. Empathic motivation may be understood as a certain kind of social motivation which is related to 'feminine' attitudes and 'secondary' control beliefs. Though empathic motivation may increase empathic accuracy in decoding emotional messages, its role for the quality of the social interaction process (e.g. with respect to empathic responding and altruism) has yet to be studied.

\section{REFERENCES}

Bakan, D. (1966). The Quality of Human Existence, Beacon Press, Boston.

Block, J. H. (1973). 'Conceptions of sex roles. Some cross-cultural and longitudinal perspectives', American Psychologist, 28: 512-526.

Brotman-Band, E. and Weisz, J. R. (1988). 'How to feel better when it feels bad: Children's perspectives on coping with everyday stress', Developmental Psychology, 24(2): 247-253.

Eisenberg, N. (1986). Altruistic Emotion, Cognition, and Behavior, Erlbaum, Hove, East Sussex.

Eisenberg, N. and Lennon, R. (1983). 'Sex differences in empathy and related capacities', Psychological Bulletin, 94(1): 100-131.

Eisenberg, N. and Strayer, J. (Eds) (1988). Empathy and its Development, Cambridge University Press, Cambridge.

Ekman, P., Friesen, W. V. and Ellsworth, P. (1972). Emotion in the Hwman Face: Guidelines for Research and an Integration, Pergamon Press, Oxford.

Flammer, A. (1990). Erfahrung der eigenen Wirksamkeit. Einführung in die Psychologie der Kontrollmeinung, Huber, Bern.

Flammer, A., Züblin, C. and Grob, A. (1988). 'Sekundäre Kontrolle bei Jugendlichen', Zeitschrift für Entwicklungspsychologie und Pädagogische Psychologie, 20: 239-262.

Foushee, H. C., Davis, M. H. and Archer, R. L. (1979). 'Empathy, masculinity, and femininity', JSAS: Catalogue of Selected Documents in Psychology, 9: 85.

Gaelick, L. V., Bodenhausen, G. and Weyer, Jr., R. S. (1985). 'Emotional communication in close relationships', Journal of Personality and Social Psychology, 49: 1246-1265.

Gilligan, C. (1982). In a Different Voice: Psychological Theory and Women's Development, Harvard University Press, Cambridge, Ma.

Goldstein, A. P. and Michaels, G. Y. (1985). Empathy, Development, Training, and Consequences, Erlbaum, Hillsdale, N. J.

Gottman, J., Notarius, C., Markman, H., Banks, S., Yoppi, B. and Rubin, M. E. (1976). 
'Behavior exchange theory and marital decision making', Journal of Personality and Social Psychology, 34: 14-23.

Haag, H. P. (1980). 'Untersuchung zum Konstrukt "Einfühlung” und seine Beziehung zur Aggression.' Unpublished dissertation. Universität Saarbrücken, Saarbrücken.

Hall, J. A. (1978). 'Gender effects in decoding nonverbal cues', Psychological Bulletin, 85: $845-858$.

Hoffman, M. L. (1977). 'Sex differences in empathy and related behaviors', Psychological Bulletin, 84: 712-722.

Ickes, W., Stinson, L., Bissonnette, V. and Garcia, S. (1990). 'Naturalistic social cognition: Empathic accuracy in mixed-sex dyads', Journal of Personality and Social Psychology, 59(4): 730-742:

Izard, C. E. (1977). Human Emotions, Plenum Press, New York.

John, H. (1988). 'Determinanten der Emotionsdekodierungsgenauigkeit bei heterosexuellen Paaren'. Unpublished diplom thesis. Technical University Aachen, Aachen.

Maccoby, E. E. and Jacklin, C. N. (1974). The Psychology of Sex Differences, Stanford University Press, Stanford, Ca.

Mehrabian, A. and Epstein, N. A. (1972). 'A measure of emotional empathy', Journal of Personality, 40: 525-543.

Parsons, T. and Bales, R. F. (1955). Family Socialization and Interaction Process, Free Press, Glencoe.

Plutschik, R. (1980). Emotion: A Psycho-Evolutionary Synthesis, Harper \& Row, New York.

Rothbaum, F., Weisz, J. R. and Snyder, S. S. (1982). 'Changing the world and changing the self: A two-process model of perceived control', Journal of Personality and Social Psychology, 42: 5-37.

Runge, T. E., Frey, D., Gollwitzer, P. M., Helmreich, R. L. and Spence, J. T. (1981). 'Masculine (instrumental) and feminine (expressive) traits. A comparison between students in the United States and West Germany', Journal of Cross-Cultural Psychology, 12:.142-162.

Spence, J. T. and Helmreich, R, L. (1978). Masculinity and Femininity: Their Psychological Dimensions, Correlates and Antecedents, University of Texas Press, Austin.

Spence, J. T., Helmreich, R. L. and Stapp, J. (1974). 'The Personal Attributes Questionnaire: A measure of sex-role stereotypes and masculinity-femininity', JSAS: Catalog of Selected Documents in Psychology, 4: 127.

Spence, J. T., Helmreich, R. L. and Stapp, J. (1975). 'Ratings of self and peers on sex-role attributes and their relation to self-esteem and conceptions of masculinity and femininity', Journal of Personality and Social Psychology, 32: 29-39.

Trommsdorff, G. (1985). 'Kontrollorientierung aus kulturvergleichender Sicht'. In: Montada, L. (Hrsg.) Bericht über die 7. Tagung Entwicklungspsychologie in Trier, Druckerei der Universität Trier, Trier, pp. 309-310.

Trommsdorff, G. (1989). 'Sozialisation und Werthaltungen im Kulturvergleich'. In: Trommsdorff, G. (Hrsg.) Sozialisation im Kulturvergleich, Enke Verlag, Stuttgart, pp. 97-121.

Trommsdorff, G. (1991). 'Child-rearing and children's empathy', Perceptual and Motor Skills, 72: $387-390$

Trommsdorff, G. (in prep.). 'Development of empathy in cross-cultural comparison'. In: Kindermann, Th. \& Valsiner, J. (Eds) Construction of Self and Social Relationships. Springer, Heidelberg/New York.

Weisz, J. R., Rothbaum, F. M. and Blackburn, T. C. (1984). 'Standing out and standing in: The psychology of control in America and Japan', American Psychologist, 34(9): 955-969.

Zuckerman, M., Blanck, P. D., DePaulo, B. M. and Rosenthal, R. (1980). 'Developmental changes in decoding discrepant and nondiscrepant nonverbal cues', Developmental Psychology, 16: 220-228.

Züblin, L. (1986). 'Wie reagieren Jugendliche in Situationen, in denen ihre Kontrolle eingeschränkt wird?' Unpublished diplom thesis. Universität Bern, Bern. 